\title{
Influence of the sample preparation method on the serotonin determination in plasma and platelets
}

\author{
Maria T. Morgadinho, C. A. Fontes Ribeiro and Tice R. A. Macedo* \\ Institute of Pharmacology and Therapeutics, Faculty of Medicine, University of Coimbra, Coimbra 3004-054, Portugal
}

Received 17 November 2003; revised 9 January 2004; accepted 19 February 2004

\begin{abstract}
Plasma or platelet serotonin concentration is commonly used to provide information about the serotonergic activity in various psychiatric or neurological diseases. Some difficulties have been described in the measurement of serotonin (5-HT) levels in plasma or platelets. We describe an isocratic liquid-chromatographic assay with amperometric detection for determination of 5-HT in the platelet pellet and in platelet-rich and platelet-poor plasma (PRP and PPP) in sample sizes of $100 \mu \mathrm{L}$ of plasma. The method uses an $\mathrm{RP}_{18}$ column and an amperometric detector with a thin-layer type electrochemical flow cell, with glassy carbon electrode maintained at a potential of $+0.600 \mathrm{~V}$ vs an $\mathrm{Ag} / \mathrm{AgCl}$ reference electrode. Determinations were performed in the presence or in the absence of plasma, since the biological matrix may affect the results. Different validation parameters were analysed: selectivity, accuracy, precision, linearity and stability. Reference values for 5-HT concentration in healthy adults $(n=12)$ were $6.6 \mathrm{nmol} / 10^{9}$ platelets, for the platelet pellet, and $5.5 \mathrm{nmol} / 10^{9}$ platelets, for PRP. The $100 \mu \mathrm{L}$ sample volume used for the preparation of PPP did not make possible the determination of 5-HT levels with accuracy and precision. Copyright (C) 2004 John Wiley \& Sons, Ltd.
\end{abstract}

KEYWORDS: serotonin measurement; platelet serotonin; plasma serotonin

\section{INTRODUCTION}

A growing body of evidence suggests that serotonin (5hydroxytryptamine, 5-HT), a central and peripheral neurotransmitter, plays an important role in regulating various physiological functions associated with neurological or psychiatric disorders (Dreux and Launay, 1985; Veenstra-Vander Weele et al., 2000; Anderson et al., 2002). Since the human brain is normally inaccessible during life for investigating various serotonergic functions, blood platelets can serve as a peripheral model for some of the central 5-HT presynaptic nerve terminals. In fact, platelets accumulate, store and release 5-HT in a manner analogous to the central serotonergic synaptosomes (Stahl, 1977, 1985; Da Prada et al., 1988). Investigations on the role of the platelet serotonergic system in health volunteers, drug abusers or in subjects with autism are a part of a program at our laboratories (Macedo et al., 2000; Coutinho et al., 2004). In the literature, normal values for human platelet 5-HT concentrations show wide variability, even when specific methods well-characterized and fully validated to quantify 5-HT were used (Flachaire et al.,

*Correspondence to: T. R. A. de Macedo, Instituto de Farmacologia e Terapeutica Experimental, Faculdade de Medicina, Universidade de Coimbra, 3004-054 Coimbra, Portugal.

E-mail: tice@ci.uc.pt

Abbreviations used: 5-HT, 5-hydroxytryptamine, serotonin; PPP, platelet-poor plasma; PRP, platelet-rich plasma.

Published online 7 July 2004

Copyright (c) 2004 John Wiley \& Sons, Ltd.
1990; Pussard et al., 1996). Since the platelets are sensitive cells, one must be sure that the in vitro separation of platelets from plasma is done without damaging the cells (Middelkoop et al., 1993). Many investigators prefer the whole-blood assay because measurements in platelets and plasma offer some difficulties, due to artefacts caused by preparation and/or sample conservation (Pussard et al., 1996; Xiao et al., 1998). Some of the factors that should be considered when a samplepreparation technique is selected are the complexity of the matrix to be assayed and the concentration of the endogenous compounds to be quantified.

In this work we developed and validated a method for the quantitative analysis of 5-HT in isolated platelets and plasma in human blood samples by reversed-phase liquid chromatography with amperometric detection. In the development of this method particular attention was paid to the biological matrix of the samples and sample handling. This method was used to measure the 5-HT platelet concentrations in platelet pellets, and in platelet-rich plasma (PRP) and platelet-poor plasma (PPP) in humans.

\section{EXPERIMENTAL}

Chromatography and quantitation. The HPLC system consisted of a 305 Gilson pump, a 231 Gilson auto sampler, a Waters Spherisorb $5 \mu \mathrm{m}$ ODS2 $4.6 \times 250 \mathrm{~mm}$ column and a 141 Gilson electrochemical detector with a glassy carbon 
electrode set at $600 \mathrm{mV}$ vs $\mathrm{Ag} / \mathrm{AgCl}$ reference electrode. The current range of the detector was set at $5 \mathrm{nA}$ full scale.

The mobile phase was a degassed solution of $0.1 \mathrm{M}$ citric acid, and $0.1 \mathrm{~m}$ sodium acetate, $\mathrm{pH}$ 3.7, containing $10 \%$ methanol, $29 \mathrm{mg} / \mathrm{L}$ sodium octylsulphate, $55.8 \mathrm{mg} / \mathrm{L}$ $\mathrm{Na}_{2}$ EDTA and $0.17 \mathrm{~mL} / \mathrm{L}$ dibutylamine, delivered at a flowrate of $1.0 \mathrm{~mL} / \mathrm{min}$. Peaks were recorded with a SP 4600 Spectra-Physics-Integrator. A peak area ratio method was used for quantitation.

Reagents. 5-Hydroxytryptamine creatinine sulphate complex and $N$-methyl-5-hydroxytryptamine (internal standard, I.S.) were purchased from Sigma. Methanol for chromatography, dibutylamine for synthesis and perchloric acid $70 \%$ (Suprapur) were obtained from Merck. All the other chemicals were of analytical grade and were purchased from Merck.

Stock solutions and Standards. Stock solutions of 5-HT $(1.00 \mathrm{mg} / \mathrm{mL})$ and I.S. $(1.00 \mathrm{mg} / \mathrm{mL})$ were prepared in $0.1 \mathrm{M}$ perchloric acid $\left(\mathrm{HClO}_{4}\right)$. The first dilution of the stock solutions at $10 \mu \mathrm{g} / \mathrm{mL}$ were stable for 15 days $(5-\mathrm{HT})$ or one week (I.S.) when stored in amber tubes at $4^{\circ} \mathrm{C}$. The working standards were prepared fresh by diluting the solutions at $10 \mu \mathrm{g} / \mathrm{mL}$ to make the required concentrations.

To determine 5-HT on the PRP a six-point calibration standard curve, ranging from 85.1 to $851.3 \mathrm{nmol} / \mathrm{L}$, was prepared by spiking the human PPP with stock 5-HT and I.S. $(25 \mu \mathrm{L} ; 700 \mathrm{pmol})$ solutions. The standard curve used to calculate the amount of 5-HT present in the platelet pellet was prepared using five different concentrations of standard solutions in $0.4 \mathrm{M} \mathrm{HClO}_{4}$, ranging from 22.7 to $567.5 \mathrm{nmol} / \mathrm{L}$. Previously, the standards were supplemented with I.S. $(25 \mu \mathrm{L}$; 700 pmol). The quality control (QC) samples in PPP and in $0.4 \mathrm{M} \mathrm{HClO}_{4}$ at three concentration levels were prepared in a similar manner.

Subjects. Twelve healthy adults (eight men and four women, aged 22-27 years old), who had not taken 5-HT-containing food during the $48 \mathrm{~h}$ period preceding blood sampling, were used for the study. Serotonin concentrations in the platelet pellet, PRP and PPP were determined.

Blood collection and sample handling. Venous blood was collected into a $10 \mathrm{~mL}$ evacuated blood tube containing liquid $\mathrm{K}_{3}$-EDTA (Middelkoop et al., 1993). Then the content of the tubes was gently mixed and centrifuged at room temperature for $10 \mathrm{~min}$ at $200 \mathrm{~g}$ (always within $2 \mathrm{~h}$ of the puncture). The resulting PRP was transferred into a polypropylene tube and $100 \mu \mathrm{L}$ was taken to count the number of platelets by using a model AI Cellcounter 134. A $100 \mu \mathrm{L}$ aliquot of PRP was centrifuged at room temperature, for $15 \mathrm{~min}$ at $1000 \mathrm{~g}$, to separate the PPP from the platelet pellet.

One of the PRP, PPP and platelet pellet aliquots was immediately analysed and the others were stored at $-80^{\circ} \mathrm{C}$ and analysed within 2 weeks.

Platelet pellet samples. The platelet pellet was resuspended in $0.4 \mathrm{M} \mathrm{HClO}_{4}(975 \mu \mathrm{L})$ and supplemented with an I.S. solution $(25 \mu \mathrm{L} ; 700 \mathrm{pmol})$ in a plastic tube. The tube was then vortex-mixed for $30 \mathrm{~s}$ and stored at $4^{\circ} \mathrm{C}$. To determine the optimal 5-HT recovery time, $15 \mathrm{~min}, 1$ and $2 \mathrm{~h}$ later the tube was vortex-mixed again and centrifuged at $1000 \mathrm{~g}$ for $2 \mathrm{~min}$, at $4^{\circ} \mathrm{C}$. A $100 \mu \mathrm{L}$ aliquot of the resulting supernatant was filtered and $25 \mu \mathrm{L}$ were injected into the chromatograph.

Platelet-rich and platelet-poor plasma samples. To $100 \mu \mathrm{L}$ of the remaining PRP and PPP we added $25 \mu \mathrm{L}$ of I.S. solution $(700 \mathrm{pmol})$. After mixing, for plasma deproteinization $875 \mu \mathrm{L}$ of $0.4 \mathrm{M} \mathrm{HClO}_{4}$ were added. The tubes were vortexmixed and stored at $4^{\circ} \mathrm{C}$. Fifteen minutes and 1 and $2 \mathrm{~h}$ later, the tubes containing PRP samples were vortex-mixed again and centrifuged at $1000 \mathrm{~g}$ for $2 \mathrm{~min}$, at $4^{\circ} \mathrm{C}$. The tubes containing PPP samples were maintained for $2 \mathrm{~h}$ before centrifugation, as indicated above. One hundred-microlitre aliquots of the resulting supernatants were filtered and $25 \mu \mathrm{L}$ were injected into the chromatograph.

Data analysis and statistics. Serotonin concentrations are expressed as $\mathrm{nmol} / 10^{9}$ platelets in platelet pellets and in $\mathrm{PRP}$, and as $\mathrm{nmol} / \mathrm{L}$ in PPP. Values are expressed as mean \pm standard deviation (SD). The precision was expressed as relative standard deviation (RSD).

Student's $t$-test was used to examine the statistical significance of the difference between 5-HT levels in the platelet pellet and PRP. The effect of the incubation period on the amount of 5-HT recovered from the PRP and platelet pellet was analysed by one-way analysis of variance (ANOVA) followed by Scheffe's and Dunnett's tests. The level of significance was accepted for $p<0.05$.

\section{RESULTS AND DISCUSSION}

\section{Optimization of chromatographic conditions}

The mobile phase that is usually used in our laboratory to analyse catecholamines, their precursors and metabolites in plasma and tissues is the same solution used in the present work but contains a lower concentration of $n$-octyl sodium sulphate ( 116.2 vs $29 \mathrm{mg} / \mathrm{L}$ used here). With these conditions it is possible to measure low catecholamine plasma levels, but regarding 5-HT the chromatographic peaks are wider and the retention times are longer $(28 \mathrm{~min})$. Therefore, experiments were performed reducing the $n$-octyl sodium sulphate proportion in the mobile phase, thus leading to narrower and higher 5-HT peaks and shortened retention time $(8.2 \mathrm{~min})$. When the $n$-octyl sodium sulphate was eliminated from the mobile phase, interference of a minor peak preceding the I.S. retention time was found in plasma samples.

\section{Selectivity}

According to the US Pharmacopoeia 24 (2000) terminology and ICH guidelines (ICH, 1995), we decided to use the term 'selectivity' when referring to this validation parameter, reserving the term 'specificity' for the procedures that are completely selective. ICH 

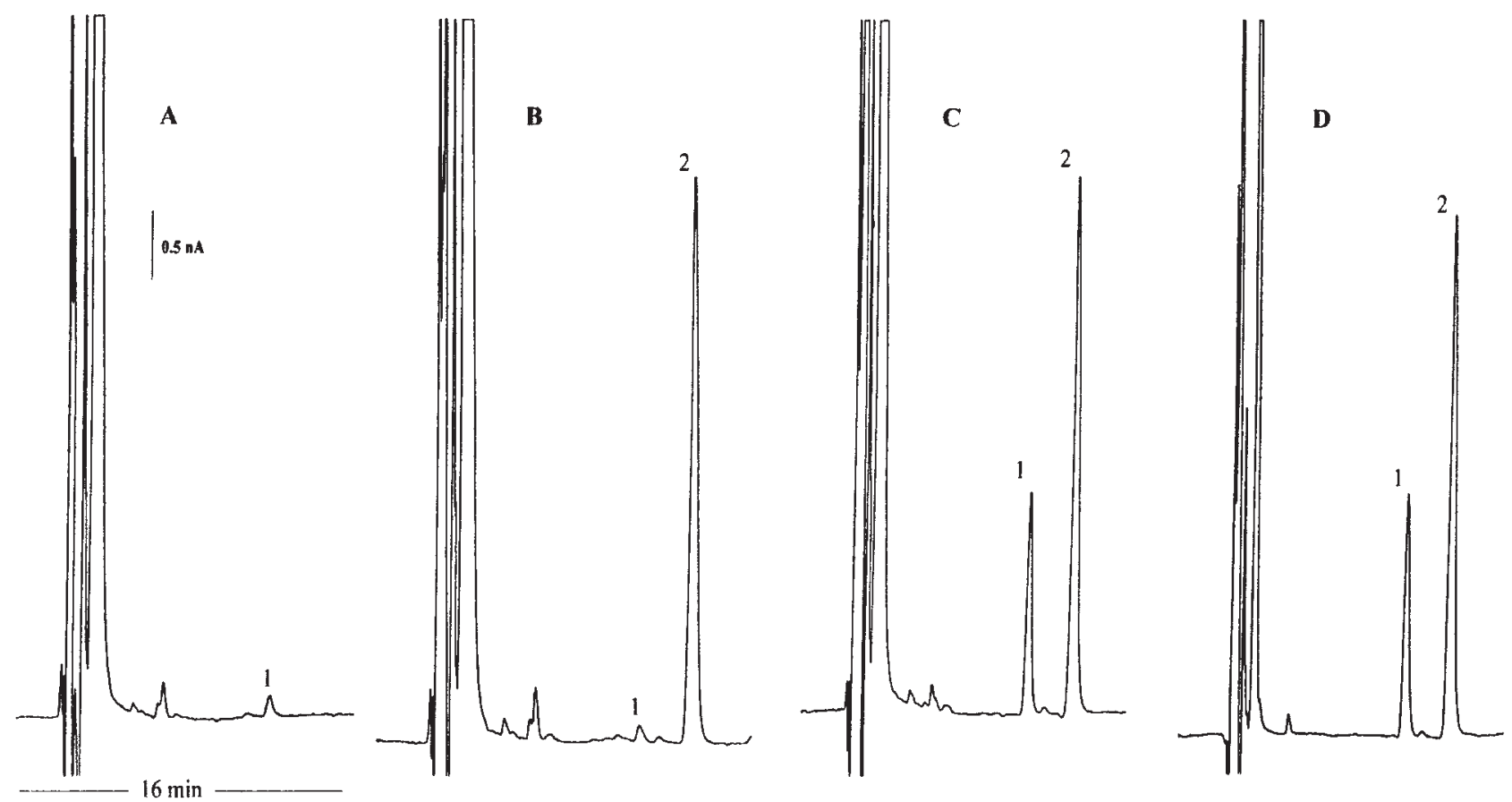

Figure 1. Selectivity chromatograms and typical chromatograms obtained from one healthy volunteer. (A) Blank plateletpoor plasma; (B) blank platelet-poor plasma spiked with internal standard; (C) platelet-rich plasma sample corresponding to a serotonin concentration of $7.42 \mathrm{nmol} / 10^{9}$ platelets; and (D) platelet pellet sample containing $7.81 \mathrm{nmol} / 10^{9}$ platelets. Peak 1, serotonin; peak 2, $N$-methylserotonin (internal standard).

Table 1. Calibration curves data obtained for the analysis of serotonin in human plasma

\begin{tabular}{|c|c|c|c|c|c|c|c|c|c|}
\hline & \multicolumn{6}{|c|}{ Nominal concentration (nmol/L) } & \multirow[b]{3}{*}{ Slope } & \multirow[b]{3}{*}{$y$-Intercept } & \multirow{3}{*}{$\begin{array}{c}\text { Correlation } \\
\text { coefficient } \\
(r)\end{array}$} \\
\hline & 85.1 & 141.9 & 283.8 & 425.6 & 567.5 & 851.3 & & & \\
\hline & \multicolumn{6}{|c|}{ Back-calculated concentration $(\mathrm{nmol} / \mathrm{L})$} & & & \\
\hline Mean $(n=3)$ & 79.9 & 146.8 & 299.4 & 411.6 & 571.5 & 859.1 & 0.0014 & 0.0669 & 0.9948 \\
\hline $\mathrm{SD}$ & 3.14 & 4.78 & 15.2 & 28.2 & 30.4 & 35.4 & 0.0001 & 0.0235 & 0.0028 \\
\hline RSD (\%) & 3.92 & 3.25 & 5.08 & 6.86 & 5.31 & 4.12 & 4.03 & 35.09 & 0.28 \\
\hline RE (\%) & -6.09 & 3.42 & 5.49 & -3.29 & 0.71 & 0.91 & - & - & - \\
\hline Recovery (\%) & 93.9 & 103.4 & 105.5 & 96.7 & 100.7 & 100.9 & - & - & - \\
\hline
\end{tabular}

guidelines define specificity as the ability to assess unequivocally the analyte in the presence of components that may be expected to be present, such as impurities, degradation products and matrix components. In practice, it is necessary to demonstrate that the assay results are unaffected by the presence of potential interferences.

PPP from 12 separate human plasmas were tested and no endogenous interference was observed at the retention time of I.S. Therefore, a minor peak of endogenous 5-HT was observed in eight of the human PPP samples (Fig. 1). The elimination of this interference is thus critical for quantitation of 5-HT in the low-nmole range; the platelet 5-HT levels are so high that endogenous interference is not significant. The selectivity and/or specificity is considered adequate if the interference does not exceed $20 \%$ of the peak for the lower limit of quantitation (FDA, 2001).

\section{Lower limit of quantitation and linearity}

The calibration curve parameters for 5-HT in PPP and in $0.4 \mathrm{M} \mathrm{HClO}_{4}$ from 3 days of validation are summarized in Tables 1 and 2, respectively. The calibration curves were linear for 5-HT in PPP, in the concentration range $85.1-851.3 \mathrm{nmol} / \mathrm{L}$, with an average regression coefficient of $0.9948 \pm 0.0028$ (Table 1), and for 5-HT in $0.4 \mathrm{M} \mathrm{HClO}_{4}$, in concentrations ranging between 22.7 and $567.5 \mathrm{nmol} / \mathrm{L}$, with a correlation coefficient of $0.9993 \pm 0.0002$ (Table 2). The fit of the calibration standards to the curves was assessed from the relative error $(\mathrm{RE}, \%): 100 \times[$ (back-calculated concentration from the regression line equation) (nominal concentration)]/(nominal concentration). For 5-HT in PPP and in $0.4 \mathrm{M} \mathrm{HClO}_{4}$, the differences for mean back-calculated concentrations were less than or equal to 6.09 and $2.66 \%$ of the theoretical values 
Table 2. Calibration curves data obtained for the analysis of serotonin in acidic medium $\left(0.4 \mathrm{M} \mathrm{HClO}_{4}\right)$

\begin{tabular}{|c|c|c|c|c|c|c|c|c|}
\hline & \multicolumn{5}{|c|}{ Nominal concentration $(\mathrm{nmol} / \mathrm{L})$} & \multirow[b]{3}{*}{ Slope } & \multirow[b]{3}{*}{$y$-Intercept } & \multirow{3}{*}{$\begin{array}{c}\text { Correlation } \\
\text { coefficient } \\
(r)\end{array}$} \\
\hline & 22.7 & 113.5 & 283.8 & 397.3 & 567.5 & & & \\
\hline & \multicolumn{5}{|c|}{ Back-calculated concentration (nmol/L) } & & & \\
\hline Mean $(n=3)$ & 22.1 & 114.7 & 290.9 & 391.3 & 574.2 & 0.0016 & 0.0240 & 0.9993 \\
\hline SD & 1.55 & 1.99 & 3.25 & 5.67 & 5.31 & 0 & 0.0018 & 0.0002 \\
\hline RSD (\%) & 6.99 & 1.73 & 1.12 & 1.45 & 0.93 & 0 & 7.37 & 0.02 \\
\hline $\mathrm{RE}(\%)$ & -2.60 & 1.04 & 2.66 & -1.52 & 1.20 & - & - & - \\
\hline Recovery (\%) & 97.4 & 101.0 & 102.7 & 98.5 & 101.2 & - & - & - \\
\hline
\end{tabular}

Table 3. Intra- and inter-day accuracy and precision of the QC samples for serotonin in human plasma (PPP) and in acidic medium (0.4 м $\left.\mathrm{HClO}_{4}\right)$

\begin{tabular}{|c|c|c|c|c|c|c|}
\hline \multirow{2}{*}{$\begin{array}{l}\text { Concentration } \\
\text { added }(\mathrm{nmol} / \mathrm{L})\end{array}$} & & \multicolumn{4}{|c|}{ Recovery (\%) } & \multirow[b]{2}{*}{ Inter-day } \\
\hline & & Day 1 & Day 2 & Day 3 & (n) & \\
\hline \multicolumn{7}{|l|}{ In $P P P$} \\
\hline \multirow[t]{3}{*}{141.9} & Mean & 102 & 107 & 101 & (6) & $104 \quad(n=18)$ \\
\hline & $\mathrm{SD}$ & 8.80 & 7.74 & 10.49 & & 9.06 \\
\hline & RSD (\%) & 8.66 & 7.21 & 10.34 & & 8.76 \\
\hline \multirow[t]{3}{*}{425.6} & Mean & 91.1 & 104 & 88.3 & (6) & $97.1 \quad(n=18)$ \\
\hline & $\mathrm{SD}$ & 6.08 & 4.02 & 8.66 & & 7.74 \\
\hline & RSD (\%) & 6.67 & 3.87 & 9.82 & & 7.74 \\
\hline \multirow[t]{3}{*}{709.4} & Mean & 97.1 & 101 & 95.5 & (6) & $99.6 \quad(n=18)$ \\
\hline & $\mathrm{SD}$ & 4.75 & 7.61 & 6.17 & & 6.77 \\
\hline & RSD (\%) & 4.89 & 7.55 & 6.46 & & 6.80 \\
\hline \multicolumn{7}{|l|}{ In $\mathrm{HClO}_{4} 0.4 \mathrm{M}$} \\
\hline \multirow[t]{3}{*}{56.8} & Mean & 98.7 & 96.5 & 103 & (4) & $99.5 \quad(n=12)$ \\
\hline & $\mathrm{SD}$ & 4.31 & 6.33 & 4.83 & & 5.57 \\
\hline & RSD (\%) & 4.36 & 6.57 & 4.68 & & 5.60 \\
\hline \multirow[t]{3}{*}{141.9} & Mean & 95.5 & 99.1 & 99.2 & (4) & $98.2(n=12)$ \\
\hline & $\mathrm{SD}$ & 3.02 & 4.94 & 3.70 & & 3.76 \\
\hline & RSD (\%) & 3.16 & 4.99 & 3.73 & & 3.83 \\
\hline \multirow[t]{3}{*}{425.6} & Mean & 100 & 99.8 & 102 & (4) & $101 \quad(n=12)$ \\
\hline & $\mathrm{SD}$ & 2.64 & 3.20 & 3.28 & & 2.90 \\
\hline & RSD (\%) & 2.64 & 3.21 & 3.22 & & 2.88 \\
\hline
\end{tabular}

$(n=3)$, in the $85.1-851.3 \mathrm{nmol} / \mathrm{L}$ and $22.7-567.5 \mathrm{nmol} /$ L concentration ranges, respectively (Tables 1 and 2). The relative standard deviation (RSD) for 5-HT did not exceed 6.86 and $6.99 \%$ in PPP and in $0.4 \mathrm{~m}$ $\mathrm{HClO}_{4}$ calibration standards, respectively (Tables 1 and 2). The lower limit of quantitation (LLOQ) was $85.1 \mathrm{nmol} / \mathrm{L}$ using a $100 \mu \mathrm{L}$ volume of human plasma

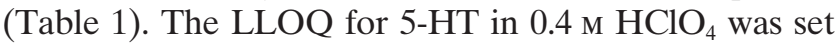
at $22.7 \mathrm{nmol} / \mathrm{L}$ (Table 2). The predefined acceptable limits of accuracy and precision for the LLOQ were 80 and $20 \%$, respectively.

\section{Accuracy and precision of the QC samples}

The intra- and inter-assay accuracy and precision of the method for 5-HT (in PPP and in $0.4 \mathrm{M} \mathrm{HClO}_{4}$ ) were determined by analysing QC samples prepared on the same day and on three different days respectively. These QC samples were prepared at low, middle and high concentrations of the corresponding calibration curve. The analysis was done for six replicates at con- centrations of $141.9,425.6$ and $709.4 \mathrm{nmol} / \mathrm{L}$, for PPP, and four replicates at concentrations of 56.8, 141.9 and $425.6 \mathrm{nmol} / \mathrm{L}$ for $0.4 \mathrm{M} \mathrm{HClO}_{4}$. The results are presented in Table 3. Accuracy was determined by calculating the mean recovery for the observed concentrations as a percentage of the nominal concentrations in standard samples. Precision was assessed from the RSD of the mean recoveries. The acceptable limits of recovery and the corresponding RSD values for QC samples were 85 and $15 \%$, respectively. As shown in Table 3, the precision and recovery for QC samples in PPP and in $0.4 \mathrm{M} \mathrm{HClO}_{4}$ were within the tolerance limits. However, intra-day accuracy and precision show less variation in the QC samples in $0.4 \mathrm{M} \mathrm{HClO}_{4}$ when compared with QC samples prepared in PPP. Therefore, the intra-day mean recoveries $(n=4)$ varied from 95.5 to $103 \%$ and the corresponding RSD values varied from 2.64 to $6.57 \%$ over the $22.7-567.5 \mathrm{nmol} / \mathrm{L}$ concentration range of 5-HT in $0.4 \mathrm{M} \mathrm{HClO}_{4}$. On the other hand, for QC samples in PPP the intra-day mean recoveries $(n=$ 6) varied from 88.3 to $107 \%$, and the corresponding 
Table 4. Effect of the incubation period with $\mathrm{HClO}_{4}(0.4 \mathrm{M})$, at $4^{\circ} \mathrm{C}$, on the 5-HT concentration (nmol/10 $10^{9}$ platelets) measured in human platelet-rich plasma and platelet pellet

\begin{tabular}{|c|c|c|c|c|c|c|}
\hline \multirow[b]{2}{*}{$\begin{array}{l}\text { Time after } \mathrm{HClO}_{4} \\
\text { addition }\left(\text { at } 4^{\circ} \mathrm{C}\right)\end{array}$} & \multicolumn{3}{|c|}{ PRP samples } & \multicolumn{3}{|c|}{ Platelet pellet samples } \\
\hline & $\begin{array}{c}5-\mathrm{HT} \\
\left(\mathrm{nmol} / 10^{9}\right)\end{array}$ & $\begin{array}{l}\mathrm{RSD} \\
(\%)\end{array}$ & $n$ & $\begin{array}{c}\text { 5-HT } \\
\left(\mathrm{nmol} / 10^{9}\right)\end{array}$ & $\begin{array}{l}\text { RSD } \\
(\%)\end{array}$ & $n$ \\
\hline $15 \mathrm{~min}$ & $3.6 \pm 1.5^{*}$ & 41 & 10 & $4.9 \pm 1.9 *$ & 39 & 10 \\
\hline $1 \mathrm{~h}$ & $5.5 \pm 2.0$ & 37 & 12 & $6.6 \pm 1.5$ & 23 & 12 \\
\hline $2 \mathrm{~h}$ & $5.7 \pm 2.0$ & 36 & 12 & $6.7 \pm 1.6$ & 24 & 10 \\
\hline $24 \mathrm{~h}$ & $5.7 \pm 2.3$ & 41 & 11 & $6.8 \pm 2.0$ & 30 & 12 \\
\hline
\end{tabular}

Values are mean $\pm \mathrm{SD} . * p<0.05$ compared with time 15 min, one-tailed Dunnet's test.

PRP, platelet-rich plasma.

RSD values varied from 3.87 to $10.34 \%$ over the $85.1-$ $851.3 \mathrm{nmol} / \mathrm{L}$ concentration range of 5 -HT in PPP.

\section{Optimization of the extraction procedure}

The 5-HT content of PRP and platelet pellets (containing $393 \pm 100 \times 10^{3}$ platelets/ $\mu \mathrm{L}$ PRP) was quantified after incubation of the samples with $\mathrm{HClO}_{4}(0.4 \mathrm{M})$ for $15 \mathrm{~min}, 1 \mathrm{~h}$ and $2 \mathrm{~h}$, at $4^{\circ} \mathrm{C}$. The amount of 5-HT recovered from both samples was maximal when the samples were incubated with $0.4 \mathrm{M} \mathrm{HClO}_{4}$ for $1 \mathrm{~h}$ (Table 4). The extracts were found to be stable at $4^{\circ} \mathrm{C}$ for $24 \mathrm{~h}$, after which there was a slow 5-HT and I.S. degradation, which was less evident for 5-HT.

\section{Stability}

The stability of 5-HT and I.S. at room temperature was evaluated over a time period that encompasses the duration of sample handling and analytical running time. In this study we have paid particular attention to the concurrent time stability of 5-HT and I.S. because indoleamines have poor stability at very low $\mathrm{pH}$ (Thorré et al., 1997). RSD of peak areas (obtained by subsequent injections of standard solutions: every $60 \mathrm{~min}$ for $6 \mathrm{~h}$ ) for 5-HT and I.S. varied between 2.3 and $3.6 \%$. The processed sample stability was evaluated by comparing the extracted platelet samples that were injected immediately after preparation (time 0 ), with the samples that were re-injected 3 and $6 \mathrm{~h}$ after sitting in the auto-sampler at room temperature. It was concluded that the processed samples are stable at room temperature for at least $6 \mathrm{~h}$. The stability of the platelet pellet and PRP samples, after 2 weeks of storage at $-80^{\circ} \mathrm{C}$ was evaluated as well. The stability evaluation involved an analysis of the low, middle and high QC samples that were stored at $-80^{\circ} \mathrm{C}$ together with fresh samples. The analysis was performed on the same day. The peak area ratio of 5-HT/I.S was determined and no differences were observed under the conditions described. RSD values remained below 3 and 9\% for platelet pellet and PRP samples, respectively.

\section{Normal values}

The mean $( \pm \mathrm{SD})$ value of the concentration of 5 -HT in the platelet pellet and in the PRP of 12 healthy adults (eight men, four women, aged 22-27 years) was $6.6 \pm$ $1.5 \mathrm{nmol}$ per $10^{9}$ platelets (range $4.4-9.0 \mathrm{nmol}$ per $10^{9}$ platelets) and $5.6 \pm 2.0 \mathrm{nmol}$ per $10^{9}$ platelets (range $3.2-10.2 \mathrm{nmol}$ per $10^{9}$ platelets), respectively. Although these values are not significantly different $(p<0.05)$, the 5-HT range determined directly in platelet pellets was narrower than that obtained in PRP.

The 5-HT concentration determined in PPP $(n=8)$ was $26 \pm 12 \mathrm{nmol} / \mathrm{L}$ (range $14-44 \mathrm{nmol} / \mathrm{L}$ ). Serotonin concentrations in PPP are very low in comparison with those in platelets and the type of anticoagulant used in blood collection is important to avoid in vitro release of 5-HT from platelets. The higher 5-HT concentration found is not in agreement with PPP normal values published when $\mathrm{K}_{3}$-EDTA was used as anticoagulant (Middelkoop et al., 1993). An explanation might be that the small plasma volume used in this analytical procedure $(100 \mu \mathrm{L})$ may not be enough to allow the quantitation of 5-HT with good accuracy and precision.

\section{CONCLUSIONS}

In this paper, the protocol for the validation of a chromatographic method to determine the 5-HT content in different platelet samples was defined in accordance with the recommendations provided by different international organizations. The criteria for data evaluation and for acceptability of the results, including the matrix effect, was examined and discussed. The complexity of the matrix in PRP samples when compared with platelet pellet samples resuspended in $\mathrm{HClO}_{4}(0.4 \mathrm{M})$ should be considered. Although no differences were observed in the 5-HT concentration in platelet pellets and PRP samples, the results show that the method for 5-HT determination in platelet pellet samples is easy to operate with better repeatability. 


\section{REFERENCES}

Anderson GM, Gutknecht L, Cohen DJ, Brailly-Tabard S, Cohen JH, Ferrari P, Roubertoux PL and Tordjman S. Serotonin transporter promoter variants in autism: functional effects and relationship to platelet hyperserotonemia. Molecular Psychiatry 2002; 7: 831 .

Coutinho AM, Oliveira G, Morgadinho T, Fesel C, Macedo TR, Bento C, Marques C, Ataíde A, Miguel T, Borges L and Vicente AM. Variants of the serotonin transporter gene (SLC6A4) significantly contribute to hyperserotonemia in autism. Molecular Psychiatry 2004; 9: 264

Da Prada M, Cesura AM, Launay JM and Richards JG. Platelets as a model of neurons. Experentia 1988; 44: 115.

Dreux C and Launay JM. Blood platelets: neuronal model in psychiatric disorders. Encephale 1985; 11: 57.

FDA. Guidance for Industry Bioanalytical Method Validation. Center for Drug Evaluation and Reseach (CDER), US Food and Drug Administration: Rockville, MD, 2001.

Flachaire E, Beney C, Berthler A, Salandre J, Quincy C and Renaud B. Determination of reference values for serotonin concentration in platelets of healthy newborns, children, adults and elderly subjects by HPLC with electrochemical detection. Clinical Chemistry 1990; 36: 2117.

ICH. ICH Guidelines. Validation of Analytical Procedures: Methodology (CPMP/ICH/281/95, Final; ICH Topic Q2B, Step 4). ICH.

Macedo TRA, Relvas J, Fontes Ribeiro CA, Pacheco F, Morgadinho MT, Gomes PC, Ventura M, Henriques V, Nunes SV,
Ramalheira C, Boto I and Vale LL. Plasma catecholamines during an ultra-rapid heroin detoxification. Annals of the New York Academy of Sciences 2000; 914: 303.

Middelkoop CM, Dekker GA, Kraayenbrink AA and PoppSnijders C. Platelet-poor plasma serotonin in normal and preeclamptic pregnancy. Clinical Chemistry 1993; 39: 1675.

Pussard E, Guigueno N, Adam O and Giudicelli J-F. Validation of HPLC-amperometric detection to measure serotonin in plasma, platelets, whole blood, and urine. Clinical Chemistry 1996; 42: 1086.

Stahl SM. The human platelet. A diagnostic and research tool for the study of biogenic amines in psychiatric and neurologic disorders Archives of General Psychiatry 1977; 34: 509.

Stahl SM. Platelets as pharmacologic models for the receptors and biochemistry of monoaminergic neurons. In: The Platelets: Physiology and Pharmacology, Longenecker GL (ed.). Academic Press: Orlando, GL, 1985; 307.

Thorré K, Pravda M, Sarre S, Ebinger G and Michotte Y. New antioxidant mixture for long term stability of serotonin, dopamine and their metabolites in automated microbore liquid chromatography with dual electrochemical detection. Journal of Chromatography B 1997; 694: 297.

US Pharmacopoeia 24/National Formulary 19, section 1225. United States Pharmacopeial Convention: Rockville, MD, 2000; 2149.

Veenstra-VanderWeele J, Anderson GM and Cook EH Jr. Pharmacogenetics and the serotonin system: initial studies and future directions. European Journal of Pharmacology 2000; 410: 165.

Xiao R, Beck $\mathrm{O}$ and Hjemdahl P. On the accurate measurement of serotonin in whole blood. Scandinavian Journal of Clinical Laboratory Investment 1998; 58: 505. 